\title{
Fetal alcohol syndrome (FAS) and fetal alcohol spectrum disorder (FASD)- diagnosis and moral policing; an ethical dilemma for paediatricians
}

\author{
Vic Larcher, Joe Brierley
}

We certainly live in interesting times; advertisements in the media and even in emergency departments enjoin those who have suffered injury to claim legal compensation from those who have wronged them, often on a 'no win no fee' basis.

Although UK paediatrics has, thus far, been largely immune to this cultural shift, it has been argued that children should be able to sue parents for illnesses that might have been prevented by vaccination, ${ }^{1}$ for wrongful birth ${ }^{2}$ or for illness caused by passive smoking. ${ }^{3}$ No such cases have succeeded in the UK, perhaps reflecting the importance the legal system attaches to the integrity of the family as a social unit.

Contrast the US, where, by 2005 more than 20 states had enacted laws criminalising women for behaviours in pregnancy considered harmful to the fetus, for example, drinking excessive alcohol. ${ }^{4}$ In the UK, considerable license is afforded to pregnant women over behaviours that may affect the welfare of their unborn children; but could this be about to change?

A recent case, heard by the upper tribunal of the Criminal Injuries Compensation Authority (CICA), ${ }^{5}$ has drawn attention to duties that might be owed to a fetus, and how competing moral claims between the mother and her fetus might be balanced. This has implications for paediatricians who may be involved in the diagnosis and management of conditions resulting from adverse maternal behaviours in pregnancy.

The case was brought by a local authority on behalf of a 6-year-old affected by fetal alcohol spectrum disorder (FASD), (rather than the more severe fetal alcohol syndrome (FAS)). ${ }^{6}$ It was accepted by all parties that the child's condition had resulted from continuing maternal alcohol consumption in pregnancy, despite warnings of the consequences for the fetus/ future child (which the mother had understood) and provision of counselling.

Paediatric Bioethics Centre, Great Ormond St Hospital, London, UK

Correspondence to Dr Joe Brierley, Great Ormond Street Hospital for Children NHS Trust, Great Ormond St, London WC1N 3JH, UK; joe.brierley@gosh.nhs.uk
The claim for compensation was initially rejected, but a subsequent tribunal allowed the claim on the grounds that a criminal injury, as defined in Section 23 of the Offences Against the Person Act (1861), had been committed. This ruling was overturned on judicial review. ${ }^{5}$ The judge accepted that alcohol-in this context a noxious agent-had effectively been maliciously administered to the fetus, but held that the fetus was not a person within the meaning of the Act. He reaffirmed that a criminal indictment of the mother was not necessary for the compensation claim. The local authority have been given leave to appeal the judgment, thus prolonging a process that has already taken over 4 years.

Subsequent media interest focussed on concerns that any successful appeal could lead to criminalisation of mothers for fetal injuries or impairment resulting from maternal behaviours during pregnancy. ${ }^{7-9}$ It was argued that harms related to a wider range of maternal behaviours might be considered culpable, though it was unclear what those behaviours were and what sanctions might be brought against those found guilty. The UK has, thus far, resisted arguments based on practice elsewhere, to make mothers criminally responsible for behaviours that might endanger the fetus, even though the latter might attract moral disapproval. Indeed a moral and legal stance on addictive and potentially harmful behaviours is no guarantee of their prevention. Quite aside from issues of causation and proof, it has also been argued that any effective change in the law to grant greater protection to the fetus would have adverse consequences on the freedoms and status of all pregnant and non-pregnant fertile women.

Maternal liberties are not the only interests involved. The child born with FAS or FASD is arguably deprived of a right to an open future because of harm suffered as a consequence of maternal behaviours. The extent to which such harms are avoidable is difficult to assess, since they may result from uncontrollable addictive behaviour or occur before the woman knows she is pregnant. However, most women who proceed with a pregnancy modify their behaviours, for example, by restricting or stopping alcohol consumption and smoking, dietary modifications and attending antenatal classes. It is reasonable to assume they do so to safeguard the welfare of the fetus as well as their own health. Those who fail to modify harmful behaviours may be subject to antenatal or postnatal child safeguarding procedures that may result in removal of the newborn. Deliberate or neglectful conduct leading to 'living' children suffering harms similar to the sequelae of FAS would lead to safeguarding procedures. Given an informed and voluntary choice to continue with pregnancy, it seems logical and morally appropriate to afford some protection to the future welfare of the child who will be born. If children could be given the option to exist with or without the consequences of FAS, it is likely they would choose the latter.

The state also has legitimate interests in safeguarding the present and future interests of its most weak and vulnerable members, as well as in the financial implications of FAS. The right of its members to act freely can be constrained so as to avoid harm to others, for example, drink driving legislation. There are growing concerns about the medical and social costs of alcohol consumption and of the economic effects of providing care for alcohol-related conditions. ${ }^{10}$ These concerns include children and young people $^{11}$ in whom overall consumption of alcohol remains worryingly high despite a fall in the numbers drinking. Alcohol abuse in younger people may be relevant to the increasing prevalence of FAS (determined by established diagnostic criteria), though overall numbers remain small (ca 150 babies per annum in England). ${ }^{12}$

Up to 7000 babies are born annually in the UK with FASD, an umbrella term for a wide range of alcohol-related birth defects of varying severity including FAS. Clinical and diagnostic features of FASD are less defined, more complex and uncertain than FAS. ${ }^{12}$ FASD prevalence varies according to setting, with higher estimates in foster and justice systems compared to community and school samples. ${ }^{13}$ Lifetime costs of medical and social care associated with FASD are difficult to quantify precisely, because deriving long-term costs from imperfect models and diagnostic imprecision are problematic, but are considerable. $^{14}$ Extrapolation from reported international prevalence rates for FASD (1\% live births $)^{12}$ provides the UK annual birth numbers quoted above. If verifiable, they imply that FASD is responsible for up to $50 \%$ UK disability births. Such epidemiological and economic considerations 
give the state clear legitimate interest in the clinical diagnosis, management and prevention of FAS and FASD.

The reported increased prevalence, diagnostic conundrums and sociolegal consequences of FASD are relevant to paediatricians and others responsible for its diagnosis and management. They may require specific training in the sensitive identification, diagnosis and management this and other conditions where antenatal maternal behaviours have affected the health of the newborn. ${ }^{15}$ Examples include drug withdrawal, sexually transmitted diseases, refusal of folic acid to prevent spina bifida, heavy smoking and intrauterine growth restriction.

The extent to which safeguarding procedures should be invoked in such cases may be unclear because the harm occurred antenatally. This contrasts with the situation postnatally where a professional has good reason to suspect that a child has suffered or is likely to suffer significant harm from the actions or neglect of parents or carers. ${ }^{16}{ }^{17}$ Here, there is a clear professional duty to report concerns to the statutory authorities, and possible censure for those who do not.

The results of any appeal in this case will be relevant for those who care for children who may have suffered in utero harms resulting from maternal behaviours, but may not resolve moral and legal dilemmas. A legal ruling that the fetus is not 'any other person' as defined in Section 23 of the Act, and lacks the legal status associated with personhood, will not dispel moral disquiets. For example, it seems plausible to argue that the fetus should have some moral status and limited protection rights, and should have means of redress if harm suffered is deliberate or avoidable. But it is doubtful that many would seek to introduce US-style fetal homicide laws, as adopted by 38 states $^{18}$ much less those holding mothers-to-be criminally responsible for behaviours-such as drug and alcohol abuse-that produce lesser harms. ${ }^{4}$

If criminalisation of women is not an answer to the problems posed by alcohol in society and those produced by FAS and FASD in particular, how may these be averted or addressed? There is general consensus that raising awareness by education and provision of support and counselling are necessary for young fertile women, perhaps as part of a wider public health and social policy initiative on reducing alcohol consumption. Because the toxic effect of alcohol on individual maternal-fetal dyads cannot be known, it has been argued that the UK should follow other countries by giving a clear message that no alcohol in pregnancy is the safest approach. ${ }^{19}$

This precautionary approach may be justified with our present knowledge of FASD. But further robust epidemiological studies are still necessary to enable appropriately sensitive and specific diagnostic criteria for FASD to be defined. Paediatricians have a role in contributing to such objective analytical studies. Indeed, this would be in keeping with their moral duties, as would the care and support of children with FAS/FASD and the identification of cases where parental behaviours cause on-going concerns. A wider role as a kind of moral policeman for parental behaviours seems inappropriate, but in any case should surely be a matter for wider political debate.

\section{Competing interests None.}

Provenance and peer review Not commissioned; externally peer reviewed.
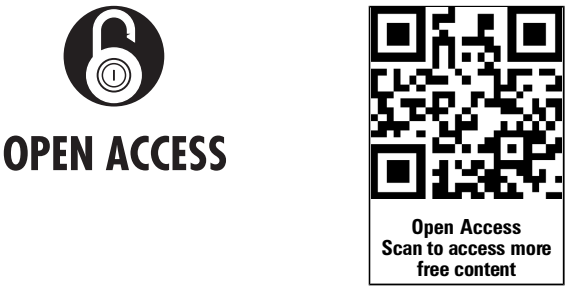

Open Access This is an Open Access article distributed in accordance with the Creative Commons Attribution Non Commercial (CC BY-NC 4.0) license, which permits others to distribute, remix, adapt, build upon this work non-commercially, and license their derivative works on different terms, provided the original work is properly cited and the use is noncommercial. See: http://creativecommons.org/licenses/ by-nc/4.0/

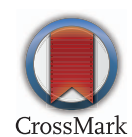

To cite Larcher V, Brierley J. Arch Dis Child 2014:99:969-970.

Received 13 May 2014

Revised 14 June 2014

Accepted 23 June 2014

Published Online First 8 July 2014

Arch Dis Child 2014;99:969-970.

doi:10.1136/archdischild-2014-306774

\section{REFERENCES}

1 Rodal R, Wilson K. Could parents be held liable for not immunizing their children? McGill J Law Health Revue de Droit et Santé De McGill 2010;4:39-64.

241 II App 2d 240, 190 N E 2d 849 (1963) and 18 N Y 2d 481 (1966)

3 Ferriman A. Children seek to sue parents over passive smoking. The independent. 1993. http://www. independent.co.uk/news/children-seek-to-sue-parentsover-passive-smoking-1481858.html (accessed 3 May 2014).
4 Linder E. Punishing prenatal alcohol abuse: the problems inherent in utilizing civil commitment to address addiction. 2005 U. III. L. Rev. 873.

5 Criminal Injuries Compensation Authority v First Tier Tribunal and CP (CIC) [2013] UK UT 0638 (AAC). https://www.west-info.eu/files/JR-1201-2011-00.pdf (accessed 3 May 2014).

6 Fetal Alcohol Syndrome: Guidelines for Referral and Diagnosis. National center on birth defects and developmental disabilities. Centers for Disease Control and Prevention. Department of Health and Human Services, 2004. http://www.cdc.gov/ncbddd/ fasd/documents/fas_guidelines_accessible.pdf (accessed 3 May 2014).

7 Court of appeal to decide whether heavy drinking while pregnant is a crime. http://www.theguardian. com/lifeandstyle/2014/mar/04/drinking-pregnantcrime-court/ http://guardianlv.com/2014/02/ pregnancy-and-drinking-could-be-criminalized/

8 http://www.birthrights.org.uk/2014/02/takingresponsiblity-for-fetal-alcohol-syndromecriminalinjuries-compensation-authority-case/

9 Howell D. BBC News website. http://www.bbc.co.uk/ news/uk-26031422 (accessed 3 May 2014).

10 Institute of alcohol studies. http://www.ias.org.uk/ Alcohol-knowledge-centre/Healthimpacts.aspx and http://www.ias.org.uk/Alcohol-knowledge-centre/ Crime-and-social-impacts.aspx (both accessed 3 May 2014).

11 Guidance on the Consumption of Alcohol by Children and Young People Sir Liam Donaldson, Chief Medical Officer December 2009. http://www. alcoholeducationtrust.org/pdfs/CMOguidance.pdf

12 Morleo M, Woolfall K, Dedman D, et al. Under reporting of foetal alcohol spectrum disorders: an analysis of hospital episode statistics. BMC Pediatr 2011;11:14. http://www.biomedcentral.com/14712431/11/14 (accessed 3 May 2014).

13 Ospina M, Dennett L. Systematic review of the prevalence of Fetal Alcohol Spectrum Disorder. Alberta, Canada: Institute of Health Economics, 2013. http://fasd.alberta.ca/documents/Systematic Prevalence_Report_FASD.pdf (accessed 3 May 2014).

14 Popova S, Stade B, Lange $S$, et al. Economic impact of fetal alcohol syndrome (FAS) and fetal alcohol spectrum disorders (FASD): a systematic literature review. Toronto: Centre for Addiction and Mental Health, 2012. ISBN 978-1-77052-992-2

15 Elliott EJ, Payne J, Haan E, et al. Diagnosis of foetal alcohol syndrome and alcohol use in pregnancy: A survey of paediatricians' knowledge, attitudes and practice. J Paediatr Child Health 2006:42:698-703.

16 HM Government. Working Together to Safeguard Children: A guide to inter-agency working to safeguard and promote the welfare of children. March 2013. https://www.gov.uk/government/ publications/working-together-to-safeguard-children (accessed 3 May 2014).

17 Safeguarding children and young people: roles and competences for health care staff: Intercollegiate document Third edition: March 2014. http://www. rcpch.ac.uk/system/files/protected/page/Safeguarding $\% 20$ Children $\% 20-\% 20$ Roles $\% 20$ and $\%$ 20Competences $\% 20$ for $\% 20$ Healthcare $\% 20$ Staff $\%$ 20\%2002\%200\%20\%20\%20\%20(3)_0.pdf (accessed 3 May 2014).

18 Pilkington, Ed (24 June 2011). 'Outcry in America as pregnant women who lose babies face murder charges'. The Guardian. http://www.theguardian. com/world/2011/jun/24/americapregnant-womenmurder-charges (accessed 3 May 2014)

19 Mukherjee RAS, Hollins S, Abou-Saleh MT, et al. Low level alcohol consumption and the foetus. $\mathrm{Br}$ Med J 2005;330:375-6. 